8) Attach on a window at eye level, a round tag with a diameter of 3-5 mm. move your eyes from distant objects behind a window on a mark and back. Repeat 10-12 times. Option: Go to the window, look closely at the close, clearly visible detail, and then direct view into the distance, trying to see the most distant objects.

9) My eyes open slowly, breathing in rhythm, gently draw a figure of eight. Repeat 5-7 times.

10) See 5-6 seconds on the thumb outstretched at eye level right hand. Slowly move the hand to the right, watch your finger, without turning his head. Do the same with the left hand. Repeat 5-7 times in each direction.

11) Often blinked eyes.

Analyzing this work, I concluded that gymnastics plays a critical role in the process. To strengthen the state of human health, disease prevention needs a meaningful relationship to the regime of work.

Production, exercise contributes to maintaining a normal physical condition of the body, and also creates conditions for a high efficiency for a long time, and the alternation of mental and physical exercise helps the body tune in to a favorable mode of the working day.

I believe that my work and the example exercises production gymnastics will contribute to attracting employees to maintain a healthy lifestyle.

\section{References:}

1. Grigorovich E. S. Production gymnastics for employees of major groups of mental work: the Method. recommendations / E. S. G., A. M. Trofimenko I. N. Malucha, Mn.: Mgmi, 2000.- 39 p

2. Regenerative medicine / ed. by V. G. Laserman. Rostov n/D, Phoenix, 2008.- 411 p.

3. Industrial gymnastics. Methodical recommendations. Tyumen: GOU VPO Tumma Roszdrava, 2009. $10 \mathrm{C}$.

4. Smolewski V. M. Textbook "Gymnastics and methods of teaching." - $24 \mathrm{p}$.

5. Educational materials for students of internal form of training - Learning materials for students of the General course (PED/f, t/f, AFC) :NSU them. P. F. Lesgaft, St. Petersburg.- 15 p.

УДК 331.57

\title{
STUDENT COMPETITION ON BUSINESS IDEAS AS A HELP TO BE EMPLOYED FOR GRADUATERS OF CREATIVE SPECIALITES
}

\author{
Liliana Naydenova \\ Irkutsk branch of the all-Russian State \\ Institute of Cinematography named after S. A. Gerasimov
}

\section{СТУДЕНЧЕСКИЙ КОНКУРС БИЗНЕС ИДЕЙ В ПОМОЩЬ ТРУДОУСТРОЙСТВУ ВЫПУСКНИКОВ ТВОРЧЕСКИХ СПЕЦИАЛЬНОСТЕЙ}

\author{
Кандитдат экономических наук, старший преподаватель Иркутского филиала ВГИК., \\ Иркутский филиал Всероссийского Государственного \\ Института Кинематографии имени С.А. Герасимова \\ 664040 г. Иркутск \\ DOI: $10.31618 /$ ESU.2413-9335.2019.5.61.41
}

\section{ABSTRACT.}

The article is devoted to solving the problem connected with unemployment of graduates which faced by many educational institutions. Especially this problem concerns graduates of creative professions, that could be explained by the lack of vacancies and specialized enterprises. One of the ways to solve this problem can be holding of specialized student scientific conferences on the base of creative Universities and Colleges. On the example of experience with students of the Irkutsk branch of VGIK we prove the effectiveness of the introduction into practice of student scientific conferences in the form of business ideas competition, as one of the methods of solving the problem of the graduates employment.

\section{АННОТАЦИЯ.}

В статье рассматривается один из способов решения проблемы трудоустройства выпускников, с которой сталкиваются многие учебные заведения. В частности, данная проблема касается выпускников творческих специальностей, что объясняется нехваткой вакантных мест и специализированных предприятий. Одним из способов решений данной проблемы может стать проведение на базе творческих ВУЗов и ССУЗов специализированных студенческих научно-практических конференций. На примере опыта работы со студентами Иркутского филиала ВГИК рассматривается эффективность внедрения в практику студенческих научно-практических конференций в виде конкурса бизнес-идей, как одного из видов разрешения проблемы трудоустройства выпускников творческих специальностей.

Keywords: independent research of students, practice outside the institution, group work of students, prevention and elimination of unemployment, creation of new jobs.

Ключевые слова: самостоятельные исследования студентов, практика вне учебного заведения, групповая работа студентов, предупреждение и устранение безработицы, создание новых рабочих мест. 
В последние годы проблема трудоустройства выпускников по специальности волнует многие ВУЗы и ССУЗы страны. Известно, что по специальности устроиться выпускнику очень сложно, а порой и невозможно, не только в мелких городах и поселках, но и в региональных центрах, поскольку рабочих мест хватает далеко не каждому. Например, Иркутский филиал ВГИК выпускает специалистов кинотехников, звукотехников, светорежиссеров, фотографов, художников-аниматоров, а скоро у нас появятся первые режиссеры-документалисты, драматурги и теле-радио продюсеры. В данный момент на официальном сайте регионального центра занятости [1] вакансий по перечисленным специальностям или вакансий по специальностям смежным с перечисленными нет. При этом, как известно, любое учебное заведение обязано формировать и сдавать ежегодный отчет по трудоустройству выпускников показывая в нем статистику трудоустройства именно по специальности, программу обучения которой студенты проходят в данном учебном заведении. В частности, нашему учебному заведению в таких условиях трудоустроить своих выпускников представляется достаточно проблематичным, хотя мы выпускаем хороших специалистов. Понятно, что не только наше, но и многие другие учебные заведения нашего города и страны сталкиваются с аналогичной проблемой по трудоустройству своих выпускников.

Как видно из сказанного выше наш ВУЗ выпускает специалистов творческих специальностей и трудоустройство выпускников по этим специальностям затруднено из-за нехватки вакантных мест и специализированных предприятий соответствующего профиля. Понимают это и наши студенты. И около четырех лет назад для, хотя бы частичного, решения вышеописанной проблемы автором доклада была организована первая студенческая конференция с названием «Фотография. Идеи для бизнеса».

Студентам выпускных курсов было предложено разбиться на подгруппы по два-четыре человека и придумать какой-либо оригинальный бизнес, базирующийся на полученных в нашем учебном заведении знаниях и умениях. Затем полностью самостоятельно просчитать и спланировать этот бизнес, проведя целое исследование - рассчитать капитальные вложения на оборудование, спланировать персонал, технологию производства, рекламу и продвижение продукции и или услуг на рынке, рассчитать себестоимость продукции и/или услуг, финансовые результаты деятельности, срок окупаемости, подобрать возможные источники финансирования, составить план погашения кредитов, подобрать оптимальную систему налогообложения, составить прогноз движения денежных средств и т.д. то есть фактически составить бизнес-план и представить проект своего бизнеса на рассмотрение своих сокурсников и жюри, состоящего из преподавателейспециалистов, преподавателей - экономистов, и студентов - будущих продюсеров. Весь проект должен оформляться в виде презентации. Результаты уже первой конференции-конкурса бизнес проектов были очень интересными и поучительными. Студенты смогли придумать и предложить нестандартные виды малого бизнеса, связанные с фотографией. И пусть небольшая часть студенческих идей для бизнеса была подсмотрена ими в интернете, в том числе на иностранных сайтах, но студентам все равно пришлось просчитать свои или чужие бизнес-идеи по текущим рыночным ценам, а значит оценить возможность действительной реализации на практике предлагаемых бизнес идей. В первый год проведения конференции были предложены такие интересные бизнес-идеи как фотография на пенке кофе, фотография на металлическом профиле, фотография - витраж на окна.

Учитывая положительные результаты первого проведения конференции, на следующий год в подготовку бизнес-проектов были вовлечены студенты других специальностей. В результате появились бизнес-планы для следующих нестандартных идей - анимированная (имеется в виду с мультипликационными картинками) книга, школа мультипликации, нестандартная школа фотографии, 3-Д изображение движущееся над залом зрителей, печать фотоизображений на 3-Д принтере, создание необычной студии звукозаписи в форме кафе-караоке и т.д.

Хочется отметить, что в ходе конкурса, особенно интересно было узнать мнение студентов продюсерского факультета, которые являлись членами жюри, т.к. это именно их задача в будущем принимать решения о потенциальной успешности того или иного проекта. А поскольку наш филиал готовит теле- и радио- продюсеров, то некоторые бизнес-идеи в области обработки звука могут быть взяты ими непосредственно для реализации.

Таким образом, во время проведения таких научно-практических конференций фактически происходит обмен бизнес идеями, которые уже были просчитаны участниками-докладчиками с большей или меньшей степенью корректности (учитывая, что это все-таки студенческие работы), что дает будущим выпускникам возможность оценить и объем требуемых капиталовложений, и примерные сроки окупаемости бизнес-проектов, уровень их рентабельности обменяться идеями по ценовой политике, проведению рекламных компаний, подбору персонала, помещений и. т. д. Также можно выделить факт того, что активность зрителей, находящихся в зале была очень высокой: студенты и жюри задавали множество вопросов выступающим, в том числе критиковали различные аспекты предлагаемых бизнес-проектов, спорили, искали слабые места.

В результате, по имеющейся у нас информации, после получения диплома четверо студентов создали свои маленькие предприятия и реализовали в них свои бизнес-идеи и идеи своих одногруппников по фотографии; двое студентов - по мультипликации; один - по созданию студий звукозаписи. В дальнейшем мы планируем создать банк интересных студенческих бизнес-идей, разместив его в электронном виде на сайте Иркутского филиала ВГИК. 
Исходя из вышесказанного можно сделать вывод, что представленная форма проведения научно - практических конференций с одной стороны побуждает студентов заниматься самостоятельными исследованиями экономических вопросов, связанных с их специальностью с другой стороны, позволяет как выпускникам, так и учебным заведениям решить проблему трудоустройства. Следовательно, опыт проведения подобных конференций может быть оценен как положительный, имеющий большое практическое значение как для выпускников учебных заведений, так и для самих учебных заведений в свете вышеописанных проблем.

Список использованных источников:

1. Министерство труда и занятости Иркутской области. б.д. :http://irkzan.ru/ (дата обращения: 14 Октябрь 2018 г.).

Информация об авторе Найденова Лилиана Валерьевна - кандидат экономических наук, старший преподаватель Иркутского филиала ВГИК., 664040 г. Иркутск, ул. Розы Люксембург 170. Еmail: o-liliana@yandex.ru

\section{СОПРОВОЖДЕНИЕ ОБРАЗОВАТЕЛЬНОГО ПРОЦЕССА КАК ПЕДАГОГИЧЕСКАЯ ПРОБЛЕМА}

Пономарева Екатерина Владимировна Аспирант МГПУ, г.Москва

\section{АННОТАЦИЯ.}

В статье рассмотрено понятие «педагогическое сопровождение» с разных авторских позиций, раскрыты формы педагогической деятельности сопровождающего взрослого, представлена классификация видов педагогического сопровождения.

Ключевые слова: сопровождение, педагогическое сопровождение, образовательный процесс, педагогическая проблема.

Давно известно, что основной акцент в современной системе образования делается на создание условий для развития и самореализации каждого ребенка. Перед любым педагогом встает вопрос о том, какие формы, методы, средства нужны для полноценного образования и развития детей. Данный вопрос может быть успешно решен ничем иным, как правильно организованным психологопедагогическом сопровождением.

Под термином «психолого-педагогическое сопровождение образовательного процесса» сегодня принято понимать целостный процесс, отличающийся своей непрерывностью изучения и анализа, формирования, развития и коррекции всех субъектов данного процесса [6]. Изучение осуществляется в целях оптимизации всего процесса обучения и воспитания, укрепления здоровья и активности детей и сотрудников для наиболее полной реализации их творческого потенциала и поддержания комфортного психического состояния.

Проблему сопровождения детей в своих трудах исследовали такие ученые как: Г.Л. Бардиер, И. Ромазан, Е.И. Казакова, В.В. Степанова, С.В. Сильченкова, Е.А. Соколова, Ф.М. Фрумина, В.А. Сластенин и др.

Понятие «сопровождение», по мнению С.В. Сильченковой берет свое начало на рубеже IX-X веков и проходит несколько исторических периодов развития [7]. Тогда сопровождение включало в себя оказание материальной помощи нуждающимся детям для их выживания. С течением времени общество стало менять свои взгляды на образованность детей, стремясь к ее повышению, что стало отправной точкой для увеличения значимости периода детства и постановки вопроса о необходимости педагогического сопровождения.
Рассматривая сопровождение как «помощь субъекту в принятии решения в ситуациях жизненного выбора», Е.И. Казакова, на наш взгляд, говорит о помощи в принятии каких-то решений, повышении качества образовательного процесса с учетом индивидуальных особенностей детей, ориентации на их потребности и возможности [4]. С мнением предыдущего автора совпадает мнение Л.М. Щипицыной, которая видит сопровождение как «метод получения субъектом защиты в процессе решения жизненных трудностей и проблем».

Согласно суждению С.А. Усковой сопровождение направленно на оказание помощи ребенку в проявлении своих индивидуальных способностей, в саморазвитии, что позволяет выбрать индивидуальную траекторию развития. Сопровождение, являясь базовой категорией современной педагогики, вмещает в себя базовые компоненты педагогического процесса - стратегию, методику, технологию воспитания и обучения [9].

По мнению, Е.А. Соколовой сопровождение включает в себя заранее спланированную деятельность, направленную на необходимость предотвращения трудностей. Сопровождение должны осуществлять специально обученные люди - педагоги - тьюторы, которые обладают определенными специфическими знаниями, умениями и навыками, обучены идеям педагогики поддержки, позволяющими так организовать помощь воспитанникам, чтобы дети смогли самостоятельно выбрать средства для ознакомления с содержанием деятельности [5].

По определению В.П. Слободчиковой и М.Ф. Фруминой сопровождение является помощью ребенку в процессе его личностного роста, установкой на открытое общение дошкольника. М.Р. Битянова относит сопровождение к профессиональной 